\title{
Study of the fundamental frequency in elderly women with hearing loss
}

\author{
Giovana dos Santos Baraldi ${ }^{1}$, Lais Castro de \\ Almeida ${ }^{2}$, Lucila Leal Calais ${ }^{3}$, Alda Cristina de \\ Carvalbo Borges ${ }^{4}$, Ingrid Gielow 5 , Mauricio \\ Raymundo De Cunto ${ }^{6}$
}

Keywords: elderly, hearing loss, voice.

\section{Summary}

\begin{abstract}
I exeased life expectancy raises demands for special attention for the elderly population; speech, language and hearing science deals with their communication disorders Hearing loss is a common disorder affecting this age group. It is known that the auditory feedback system is essential to human vocalizing, as it organizes voice production. Aim: To assess and correlate the hearing system and the Fundamental Frequency (F0) of women who have variable degrees of sensorineural hearing loss. Material and Method: a crosssectional descriptive study. 30 women with a mean age of 75.95 (SD $=7,41$ ) were included. Inclusion criteria were: symmetric sensorineural hearing loss, a high-frequency sloping configuration, and a type A tympanogram. Subjects underwent Pure Tone Audiometry, a Word Recognition Test, Tympanometry, and Voice Assessment. Results: Patients with higher degrees of hearing loss showed an increased fundamental frequency. Conclusion: In aged individuals with hearing loss, audiovocal monitoring is altered, resulting in voice parameter changes.
\end{abstract}

${ }^{1}$ Master's degree in science, UNIFESP. Speech therapist. 2 Master's degree in science, Sao Paulo Federal University - Paulista Medical School. Speech therapist. ${ }^{3}$ Master's degree in science, Sao Paulo Federal University - Paulista Medical School. Speech therapist.

${ }^{4}$ Doctor in Communication Disorders, UNIFESP. Adjunct professor at UNIFESP/ Paulista Medical School. ${ }^{5}$ Doctor in Communication Disorders, UNIFESP/Paulista Medical School. Professor at UNIFESP/Paulista Medical School

${ }^{6}$ Graduate student (master's degree) in biosafety, USP - Sao Carlos. Electronic engineer. Sao Paulo Federal University.

Address for correspondence: Praca Alberto 87 Jardim Belgica Sao Paulo 04672-130.

Paper submitted to the ABORL-CCF SGP (Management Publications System) on June 2nd, 2006 and accepted for publication on August 3rd, 2006. cod. 2048. 


\section{INTRODUCTION}

Brazilian demography has changed significantly in past decades according to data from the Brazilian Institute of Geography and Statistics. ${ }^{1}$ In 2003 the life expectancy at birth for both genders reached 71.3 years, an increase of 0.8 years compared to 2000 ( 70.5 years). This change in Brazilian demography has led to an increase in the number of elderly people and their specific health needs. In this scenario we have seen the development of speech therapy for the elderly and frequent studies on hearing and voice. Presbycusis, or age-related hearing impairment, is sensorineural hearing loss with a gradual sloping configuration. ${ }^{2}$ Presbyphonia is the aging voice, which includes voice tremor, increased intensity, and a soprous and harsh quality of voice. ${ }^{3}$ Hearing and voice operate jointly in communication, where hearing monitors voice production. Monitoring one's own voice is essential for good communication; the auditory system is able to regulate voice parameters such as intensity, extension and frequency. One of the most frequently studied voice parameters in the literature is the fundamental frequency $\left(\mathrm{F}_{0}\right)$. $\mathrm{F}_{0}$ is physiologically determined by the number of cycles that vocal folds produce in a second, or the number of repeated glottal cycles. ${ }^{4}$ The mean $\mathrm{F}_{0}$ for adult women (aged between 18 and 45 years) that speak Brazilian Portuguese is $204 \mathrm{~Hz}$. The $\mathrm{F}_{0}$ decreases with age; in women over 45 years it decreases to about $191 \mathrm{~Hz}{ }^{5}$ As age progresses, changes of the $\mathrm{F}_{0}$ are related not only to anatomical and physiological alterations of the larynx, but also to the difficulty of monitoring voice as a result of age-related hearing loss.

The aim of this paper was to assess and to correlate hearing and voice $\mathrm{F}_{0}$ values in elderly patients with varying degrees of auditory sensitivity.

\section{MATERIAL AND METHODS}

This study was analyzed and approved by the Research Ethics Committee of the Sao Paulo Federal University for research on human beings under the protocol number CEP 1189/04 of the National Health Council. The study sample included 30 female subjects aged between 60 and 93 years (mean 76.23 years, standard deviation $=8.17$ ) referred from the Geriatrics and Gerontology Institute of the Sao Paulo Federal University (UNIFESP). The evaluation of hearing and voice was done between June 2004 and May 2005. Subjects underwent basic assessments of hearing and voice in an acoustic booth as follows:

- pure tone audiometry: measuring of air conduction audiometry thresholds at 250 to $8000 \mathrm{~Hz}$ and bone conduction auditory thresholds at 500 to $4000 \mathrm{~Hz}$ in both ears. The descending method was used for measuring thresholds with both transducers, using audible and inaudible sound, as proposed by Carhart \& Jerger. ${ }^{6}$ This procedure includes the following steps: a) the sound stimulus is presented at an easily perceived intensity; b) intensity is reduced at $10 \mathrm{~dB}$ intervals until the stimulus becomes inaudible; c) intensity is increased at $5 \mathrm{~dB}$ intervals until the subjects once again perceives sound. The audibility threshold is considered as the lowest intensity level at which subjects responds to two of four presentations according to the steps described above.

- voice audiometry: investigation of the speech recognition threshold (SRT) and the speech recognition percentage rate (SRPR). The SRT was obtained by a descending procedure using disyllables presented directly. Subjects were asked to repeat the speech stimulus. The lowest intensity level at which subjects recognized $50 \%$ of the stimuli - two of four words presented - was defined as the speech recognition threshold. The SRPR, a supraliminar test to establish the listener's ability to recognize speech stimuli under ideal listening conditions, was investigated using an initial intensity $40 \mathrm{~dB}$ over tone threshold means at 500, 1000 and $2000 \mathrm{~Hz}$. If patients reported discomfort, the intensity was reduced in $10 \mathrm{~dB}$ steps until the patient reported the best intensity for obtaining the percentage rate of speech recognition. Stimuli were presented orally. The list of 25 phonetically balanced monosyllables we used was proposed by Pen and Mangabeira.

- acoustic immitance testing: tympanometry and investigation of contralateral acoustic reflections, done to discard middle ear involvement. Tympanometry permits inferences on the mobility of the tympanic and ossicular systems; acoustic reflection thresholds correspond to the lowest intensity that can alter static compliance.

Audiometries were classified according to two criteria, as follows:

1. Silman, Silverman': classification of the degree of sloping losses using mean frequencies of 500, 1000 and $2000 \mathrm{~Hz}$, and of 2000, 3000 and $4000 \mathrm{~Hz}$. A degree of loss was given for low frequencies $(500 \mathrm{~Hz}, 1$ and $2 \mathrm{KHZ})$ and another for high frequencies (2, 3 and $4 \mathrm{KHZ}$ ).

2. Lloyd, Kaplan': classification of the sloping audiometric configuration according to threshold differences between octaves; descending configurations are classified as flat, gradual, sloping and abrupt.

Subjects were instructed to issue the vowel /a/ naturally, at usual intensity and frequency, in a prolonged and sustained manner, and to count the numbers 1 to 10 (sample of connected speech). Voices were recorded in an acoustic booth where maximum noise was $60 \mathrm{~dB}$; subjects were seated during recordings. A preamplifier, a VHS stereo HI-FI system and an Audio 20 Plantronic microphone were used for voice recording, as recommended by De Cunto and Menezes (2004).10 Voice samples were digitized at a sample frequency of $32000 \mathrm{~Hz}$ using the Sound Forge software, version 4.5. Acoustic analysis was done using the CSL software from Kay Elemetrics Corporation, version 1993/1994, module MVDP, from which the fundamental 
frequency was extracted.

After auditory and voice assessment, data was analyzed statistically using the Kruskal-Wallis, Mann-Whitney, chi-square and equality of two proportions non-parametric tests. The significance level was 0.10 (10\%).

\section{RESULTS}

Starting with pure tone audiometry, right and left ear results were compared to check for symmetry between ears, as published papers have suggested that the left ear performs better in presbyacusis subjects. ${ }^{12}$ There was no statistically significant difference between ears in this study; ears were therefore analyzed jointly. As a result of this there were 30 ears for 30 subjects in our analysis.

Table 1. Distribution of auditory sensitivity degrees and the audiometric configuration for low and high frequencies for both ears. $(n=60)$.

\begin{tabular}{|c|c|c|c|}
\hline & Gender & female & \\
\hline & & $\mathrm{n}$ & $\%$ \\
\hline \multirow{6}{*}{$\begin{array}{l}500 \mathrm{~Hz}, 1 \text { and } \\
2 \mathrm{KHz}\end{array}$} & normal & 23 & $28.3 \%$ \\
\hline & mild & 16 & $26.7 \%$ \\
\hline & moderate & 18 & $30 \%$ \\
\hline & moderate-severe & 6 & $10 \%$ \\
\hline & severe & 3 & $5 \%$ \\
\hline & total & 60 & $100 \%$ \\
\hline \multirow[t]{6}{*}{ 2, 3 and $4 \mathrm{KHz}$} & normal & 11 & $18.3 \%$ \\
\hline & mild & 7 & $11.7 \%$ \\
\hline & moderate & 20 & $33.3 \%$ \\
\hline & moderate-severe & 15 & $25 \%$ \\
\hline & severe & 7 & $11.7 \%$ \\
\hline & total & 60 & $100 \%$ \\
\hline \multirow[t]{5}{*}{$\begin{array}{l}\text { audiometric } \\
\text { configuration }\end{array}$} & flat & 9 & $15 \%$ \\
\hline & gradual & 28 & $46.7 \%$ \\
\hline & abrupt & 17 & $28.3 \%$ \\
\hline & Rampa & 6 & $10 \%$ \\
\hline & total & 60 & $100 \%$ \\
\hline
\end{tabular}

\section{DISCUSSION}

Hearing and voice systems change with age. The acuity and sensitivity of hearing, and the accuracy, speed, resistance and coordination of voice all decrease with aging. These changes go hand in hand with other bodily changes, and vary from person to person and according to each organism and lifestyle. Studies on the influence of hearing on voice production in the elderly are not frequent in the literature; there have been few studies correlating both systems. There have been reports from authors such as those by Shindo and Hanson ${ }^{12}$ showing that hearing loss and dependency in the elderly exacerbate the impact of dysphonia. Notwithstanding the lack of studies on hearing and voice production, auditory methods have been successfully employed in the rehabilitation of dysphonia, based on the principle that improved hearing positively affect voice production.13 Based on this principle, it is easy to imagine how the hearing and voice systems are interrelated, and how adaptation of an individual hearing aid in an hearing-impaired elderly patient can help improve auditory sensitivity and voice production, reduce voice tension and intensity, and prevent damage to the phonatory system.

The fundamental frequency, one of the most studied voice production parameters, may be directly related to the auditory monitoring capability. There are studies showing that when auditory monitoring is altered, the $\mathrm{F}_{0}$ voice parameter also changes. ${ }^{14}$ Table 1 shows the distribution of degrees of hearing loss at low and high frequencies, and the distribution of audiometric configurations. Moderate loss predominated at low frequencies (30\%), followed by normal hearing (28.3\%) and mild loss (26.7\%). The similar analysis applied to high frequencies shows that moderate loss predominated $(33,3 \%)$, followed by moderate-severe loss (25\%) and severe loss (11.7\%). These findings are similar to those of Katsarkas and Ayukawa, which investigated 68 subjects aged over 50 years; most of these subjects had normal hearing or mild hearing loss at low frequencies, and $37 \%$ of subjects had moderate and severe loss at high frequencies. ${ }^{11}$ Other papers have suggested that elderly subjects have increased high frequency thresholds, particularly over $3 \mathrm{KHz},{ }^{15-17}$ showing that frequency loss is more significant at higher frequencies. Studies on elderly subjects commonly report a lower auditory threshold at high frequencies in elderly patients.

The classification of audiometric configurations was also used in parallel with the degree of severity. The gradual configuration (41.3\%) predominated, followed by the abrupt configuration (33.,8\%), the flat configuration (12.5\%) and the sloping configuration (12.5\%). These results suggest that the most recurring configuration in the elderly was the gradually sloping type, in which there is an auditory threshold difference between audiogram octaves of more than 5 to $12 \mathrm{~dB}$. Other authors that investigated the same age group have reported that most of the subjects had a downward sloping audiometric configuration where losses occur over 2kHz.18 A study of 331 elderly subjects of both genders also showed that a sloping audiometric configuration was more frequent. ${ }^{19}$

Table 2 shows audiometric findings in detail, where the correlation between the $\mathrm{F}_{0}$ of sustained issuing of vowel "a", the sample of connected speech and the degree of 
Table 2. Correlation of $F_{0}$ values for sustained issuing of vowel "a" and the sample of connected speech with the degree of loss at $500 \mathrm{~Hz}, 1$ and $2 \mathrm{KHz}$.

\begin{tabular}{|c|c|c|c|c|c|c|}
\hline $500 \mathrm{~Hz}, 1$ and $2 \mathrm{KHz}$ & mean & standard deviation & minimum & maximum & $p$-value & \multirow[b]{2}{*}{0.001 * } \\
\hline \multirow{5}{*}{$\mathrm{F}_{0} / \mathrm{a} /(\mathrm{Hz})$} & normal & 163.82 & 39.44 & 68.0 & 207.9 & \\
\hline & mild & 144.44 & 29.04 & 85.8 & 192.3 & \multirow{9}{*}{0.104} \\
\hline & moderate & 160.30 & 33.57 & 85.8 & 213.5 & \\
\hline & moderate-severe & 188.23 & 5.32 & 182.4 & 196.8 & \\
\hline & severe & 201.27 & 10.63 & 195.1 & 213.5 & \\
\hline \multirow{5}{*}{$\mathrm{F}_{0}$ speech $(\mathrm{Hz})$} & normal & 187.65 & 34.95 & 138.2 & 269.7 & \\
\hline & mild & 185.45 & 37.94 & 137.9 & 250.3 & \\
\hline & moderate & 187.15 & 23.65 & 148.8 & 250.3 & \\
\hline & moderate-severe & 181.97 & 23.61 & 151.6 & 200.2 & \\
\hline & severe & 258.78 & 27.05 & 227.5 & 274.4 & \\
\hline
\end{tabular}

Key: F0 = fundamental frequency

Table 3. Correlation of $F_{0}$ values for sustained issuing of vowel "a" and the sample of connected speech with the degree of loss at 2,3 and $4 \mathrm{KHz}$.

\begin{tabular}{|c|c|c|c|c|c|c|}
\hline 2,3 e $4 \mathrm{KHz}$ & mean & standard deviation & minimum & maximum & $p$-value & \multirow[b]{2}{*}{$0.004^{*}$} \\
\hline \multirow{4}{*}{$\mathrm{F}_{0} / \mathrm{a} /(\mathrm{Hz})$} & normal & 169.43 & 34.33 & 68.0 & 187.4 & \\
\hline & mild & 137.22 & 41.39 & 68.0 & 207.9 & \multirow{7}{*}{$0.001 *$} \\
\hline & moderate-severe & 174.37 & 29.07 & 85.8 & 207.9 & \\
\hline & severe & 170.02 & 56.61 & 85.8 & 213.5 & \\
\hline \multirow{4}{*}{$\mathrm{F}_{0}$ speech $(\mathrm{Hz})$} & mild & 154.32 & 19.40 & 137.9 & 183.8 & \\
\hline & moderate & 189.63 & 21.91 & 143.4 & 235.1 & \\
\hline & moderate-severe & 183.31 & 29.19 & 148.8 & 250.3 & \\
\hline & severe & 234.16 & 34.36 & 189.3 & 274.4 & \\
\hline
\end{tabular}

Table 4. Correlation of $F_{0}$ values for sustained issuing of vowel "a" and the sample of connected speech and audiometric configuration.

\begin{tabular}{|c|c|c|c|c|c|c|}
\hline configuration & mean & standard deviation & minimum & maximum & $\mathrm{p}$-value & \\
\hline \multirow{3}{*}{$\mathrm{F}_{0} / \mathrm{a} /(\mathrm{Hz})$} & abrupt & 147.78 & 47.86 & 68.0 & 213.5 & 0.147 \\
\hline & gradual & 169.73 & 22.47 & 132.4 & 213.5 & \\
\hline & sloping & 138.72 & 42.30 & 90.2 & 184.7 & \\
\hline \multirow{3}{*}{$\mathrm{F}_{0}$ speech $(\mathrm{Hz})$} & abrupt & 176.32 & 38.08 & 137.9 & 250.3 & $0.052^{*}$ \\
\hline & flat & 191.63 & 30.30 & 173.0 & 269.7 & \\
\hline & sloping & 189.85 & 5.69 & 183.8 & 196.5 & \\
\hline
\end{tabular}


hearing loss at low frequencies may be seen. The mean $\mathrm{F}_{0}$ for subjects with mild hearing loss $(144.44 \mathrm{~Hz})$, moderate hearing loss $(160.30 \mathrm{~Hz})$, moderate-severe hearing loss $(188.23 \mathrm{~Hz})$ and severe hearing loss $(201.27 \mathrm{~Hz})$ leads to the conclusion that the $\mathrm{F}_{0}$ value after sustained issuing of the vowel "a" was significantly increased at low frequency hearing loss. No significant difference was found in the comparison of $\mathrm{F}_{0}$ values of the connected speech sample and low frequency degrees. Table 3 shows the correlation between the same $\mathrm{F}_{0}$ values and high frequencies, where a significant difference was found for both vowel "a" and connected speech. Mean $\mathrm{F}_{0}$ values for sustained issuing of the vowel "a" and the connected speech sample were as follows: 137.22 and $154.32 \mathrm{~Hz}$ (mild hearing loss), 154.23 and $189.63 \mathrm{~Hz}$ (moderate hearing loss), 174.37 and 183.31 $\mathrm{Hz}$ (moderate-severe hearing loss), and 170.02 and 234.16 $\mathrm{Hz}$ (severe hearing loss). We noted that $\mathrm{F}_{0}$ is significantly increased in severe high frequency hearing loss both for the sustained vowel and the connected speech sample. There are few published papers relating the $\mathrm{F}_{0}$ voice pattern to hearing loss. Weatherley et al. analyzed fundamental frequency measurements in 19 normal-hearing subjects and compared them with measurements in 21 subjects with hearing loss. The mean $\mathrm{F}_{0}$ value for these subjects (all aged over 60 years) was $189.68 \mathrm{~Hz}$ for women with hearing loss; no difference was seen between subjects with hearing loss and normal-hearing subjects. 20 An increased $\mathrm{F}_{0}$ in severe hearing loss may be explained by studies on auditory monitoring that report increased $\mathrm{F}_{0}$ values with reduced auditory monitoring. 14 Subject in our study all had hearing loss, so it may be assumed that increased mean $\mathrm{F}_{0}$ values were due to decreased auditoryvoice monitoring.

$\mathrm{F}_{0}$ values were also correlated with audiometric configurations. Table 4 shows the correlation between the $\mathrm{F}_{0}$ of sustained issuing of vowel "a", the connected speech sample and audiometric configurations. We noted a statistically significant difference between the connected speech sample $\mathrm{F}_{0}$ and audiometric configurations. The mean $\mathrm{F}_{0}$ value was low for the abrupt configuration $(176.32 \mathrm{~Hz}$ ) compared to the flat configuration $(191.63 \mathrm{~Hz})$, the gradual configuration (197.61 Hz) and the sloping configuration (189.85 HZ). The conclusion is that the $\mathrm{F}_{0}$ mean was higher in the gradually sloping audiometric configuration, in which there is a 5 to $12 \mathrm{~dB}$ difference in auditory thresholds between frequency octaves.

Our data suggest the auditory feedback regulates voice production by monitoring different voice parameters. In the elderly it is clear how hearing loss and voice changes are related. Hearing affects voice production by changing its parameters, especially in subjects with marked hearing loss. These indicators point to the need for early auditory rehabilitation and routine assessments of voice disorders in the elderly. Early auditory rehabilitation in elderly patients may help reduce voice changes, directly affecting communication and social interaction.

\section{CONCLUSION}

The fundamental frequency $\left(\mathrm{F}_{0}\right)$ of a sustained vowel was increased in marked low and high frequency hearing loss. The fundamental frequency $\left(\mathrm{F}_{0}\right)$ of the connected speech sample was increased in the sloping audiometric configuration where marked loss was seen over $2 \mathrm{KHz}$.

\section{REFERENCES}

1. Fundação do Instituto Brasileiro de Geografia e Estatística. Diretoria de Pesquisas, Censos Demográficos, IBGE. Brasília 2003. Disponível em: http//www.ibge.gov.br Acessado em 25 de maio de 2005

2. Sangster JF, Gerace TM, Seewald RC. Hearing loss in elderly patients in a family practice. Can Med Assoc J 1991;144(8):9814.

3. De Biase NG, Cervantes O, Abrahão M. A voz no idoso. Acta AWHO 1998;17(2):70-2.

4. Behlau M, Madazio G, Feijó D, Pontes P. Avaliação de voz. In: Behlau M. (organizadora). Voz: O livro do Especialista - vol I. São Paulo: Revinter; 2001. p.139-76.

5. Behlau M, Pontes P. Avaliação e tratamento das disfonias. São Paulo: Revinter; 1995. p. 49-52.

6. Carhart R, Jerger J. Preferred method for clinical determination of pure tone thresholds. J Speech Hear Disord 1959;24:33045.

7. Pen MG, Mangabeira Albernaz PL. Desenvolvimento de testes para logoaudiometria: discriminação vocal. In: II Congresso Pan Americano de Otorrinolaringologia Y Broncoesofalogia, Lima - Peru. Anales. Lima - Peru, 2:223-6, 1973.

8. Silman S, Silverman CA. Basic audiologic testing. In: Silman S, Silverman CA. Auditory diagnosis principles and applications. San Diego: Singular Publishing Group; 1997. p. 44-52.

9. Lloyd LL, Kaplan H. Audiometric interpretation: a manual of basic audiometric. Baltimore: University Park Press; 1978.

10. De Cunto MR, Menezes MHM. Gravação de voz em videocassete: uma opção de qualidade. Anais do XII Congresso Brasileiro de Fonoaudiologia Foz do Iguaçu, Brasil; 2004 p 27-30.

11. Katsarkas A, Ayukawa H. Hearaing loss due to aging (presbycusis). J. Otolaryngol. 1996;15(4):239-44.

12. Shindo M, Hanson D. Geriatrics voice and laryngeal dysfunction. Otolaryngol Clin North Am 1990;23:1035-44.

13. Behlau M, Madazio G, Feijó D, Azevedo R, Gielow I, Pontes P. Aperfeiçoamento vocal e tratamento fonoaudiológico das disfonias. In: Behlau M (organizadora). Voz: O livro do Especialista - Vol. II. São Paulo: Revinter; 2005 p. 417-525.

14. Burnett TA, Senner JE, Larson CR. Voice FO responses to pitch-shifted auditory feedback: a preliminary study. J Voice 1997;11(2):202-11.

15. Mazelova J, Popelar J, Syka J. Auditory function in presbycusis: peripheral vs. central changes. Exp Gerontol 2003;38:87-94.

16. Moscicki EK, Elkins EF, Baum HM, Mcnamara PM. Hearing loss in the elderly: epidemiologic study of the framingham heart study cohort. Ear Hear 1985;6:184-90.

17. Lee FS, Matthews LJ, Dubno JR, Mills JH. Longitudinal study of pure-tone thresholds in older persons. Ear Hear 2005;26(1):111. 
18. Soncini F, Costa M, Oliveira J, Tochetto MT. Perfil audiológico de indivíduos na faixa etária entre 50 e 60 anos. Fono Atual 2004;7(28):21-9.

19. Jurca APK, Pinheiro FCCP, Martins KC, Herrera LF, Colleone LM, Saes SO. Estudo do perfil audiológico de pacientes com idade acima de 60 anos. Salusvita 2002;21(1):51-8.
20. Weatherley CC, Worrall LE, Hickson LM. The effect of hearing impairment on the vocal characteristics of older people. Folia Phoniatr Logop 1997;49(2):53-62. 